\title{
Localisation and characterisation of dystrophin in the central nervous system of controls and patients with Duchenne muscular dystrophy
}

Makoto Uchino, Hitoh Teramoto, Hiroaki Naoe, Kowashi Yoshioka, Teruhisa Miike, Masayuki Ando

\begin{abstract}
The aim was to localise and characterise dystrophin in various human tissues, especially in the CNS. Immunoblotting and immunostaining studies were carried out with eight region-specific dystrophin antibodies. In necropsy tissue from controls, dystrophin was noted as a doublet in immunoblots of striated muscle, and as a single band in those of smooth muscle and the CNS. With immunostaining, punctate immunoreactivity was seen on the cell bodies and dendrites of the cerebral cortical neurons and cerebellar Purkinje cells. By contrast, dystrophin was not detected in any tissues, including the cerebrum and cerebellum, of patients with Duchenne muscular dystrophy who had an intellectual disturbance.
\end{abstract}

$(F$ Neurol Neurosurg Psychiatry 1994;57:426-429)

First Department of Internal Medicine, Kumamoto University Medical School, 1-1-1 Honjo, Kumamoto 860, Japan M Uchino

$M$ Ando

Department of Neurology, Saishunso

Hospital, 2656

Nishigoshi,

Kumamoto 861-11, Japan

H Teramoto

H Naoe

Department of Child

Development,

Kumamoto University

Medical School, 1-1-1

Honjo, Kumamoto

860, Japan

K Yoshioka

T Miike

Correspondence to: Dr M Uchino, First Department of Internal Medicine, Kumamoto University Medical School, 1-1-1 Honjo, Kumamoto, Japan.

Received 14 April 1993 and in final revised form 6 July 1993. Accepted 9 August 1993
Dystrophin is a large protein (molecular weight $427 \mathrm{kDa}$ ) that is absent or greatly reduced in patients with Duchenne muscular dystrophy. ${ }^{1-3}$ Dystrophin was found by immunostaining to be localised on the surface membrane of striated and smooth muscle. ${ }^{4-8}$ In mice, dystrophin has recently been found not only in muscles but also in the CNS, ${ }^{9}$ which is unrelated to contraction and relaxation. This suggests that dystrophin is concerned with diversified physiological functions.

Even before dystrophin was identified, it was well known that children with Duchenne muscular dystrophy often had a slight or moderate mental retardation. The mean IQ is about 80 and remarkably similar in the many reported series. ${ }^{10-17}$ Although opinions have differed as to whether this is a primary phenomenon closely related to the course of the disease or a secondary effect caused by muscle dysfunction and lack of educational opportunity, the first idea is predominant currently. tion of dystrophin in various human tissues, especially in the CNS, a study was carried out with eight region-specific dystrophin antibodies.
To clarify the characteristics and localisa-

\section{Materials and methods}

Necropsy specimens of skeletal muscle, cardiac muscle, stomach, lung, liver, kidney, bladder, cerebrum (frontal lobe, parietal lobe, occipital lobe), cerebellum, and spinal cord were taken from normal controls ( 42 to 74 years old) who died of non-neuromuscular diseases, one patient with Kennedy-AlterSung disease (62 years old), one patient with myotonic dystrophy (54 years old), and three patients with Duchenne muscular dystrophy $(17,20$ and 26 years old); these three patients were intellectually disturbed. Necropsy was performed within four hours of death. Specimens from patients with Duchenne muscular dystrophy were collected within two hours.

For immunoblotting procedures, tissues were homogenised in a buffer containing $2 \%$ sodium dodecyl sulphate (SDS) $5 \% \beta$-mercaptoethanol, $4 \mathrm{mM}$ EDTA, $1 \mathrm{mM}$ phenylmethylsulfonyl fluoride (PMSF), $40 \mathrm{mM}$ Tris, $0.24 \mathrm{M}$ glycine, $40 \%$ glycerine, and $0.001 \%$ bromphenol blue ( $\mathrm{pH} 8 \cdot 5$ ). About 6 $\mu \mathrm{l}$ of sample buffer containing $60 \mu \mathrm{g}$ protein for the striated muscle and $12 \mu \mathrm{l}(120 \mu \mathrm{g}$ protein) for the smooth muscle and brain were loaded on to 10 -well 3.5 to $12 \%$ gradient SDS-polyacrylamide gels $(1 \mathrm{~mm} \times 10 \mathrm{~cm} \times 9$ $\mathrm{cm})$. After transfer into the nitrocellulose membrane, the specimen was blocked with $10 \%$ skimmed milk and blots were stained with dystrophin antibody at room temperature for two hours. The dystrophin-antidystrophin immune complex was detected with affinity-purified secondary antibody conjugated to avidin-DH biotinylated horseradish peroxidase (Vecstain ABC kit and Elite ABC kit, Vector Laboratories, USA). Eight kinds of region-specific dystrophin antibodies were used: sheep dystrophin antibodies $(60 \mathrm{kDa}$, $30 \mathrm{kDa}$ polyclonals, the original antibodies of Hoffman et $a^{2}$ ), rabbit dystrophin antibodies (P-20, DMD peptide IV, and antibody 6-10), and mouse dystrophin antibodies (DYS-1, DYS-2, and DYS-3; Novocastra Laboratories, UK). P-20 and DMD peptide IV were polyclonal antibodies raised against the 1750-2248 and 3495-3544 amino acids of dystrophin, respectively. Antibody 6-10 was a polyclonal antibody produced in a rabbit immunised with a dystrophin polypeptide expressed in bacteria from dystrophin cDNA 


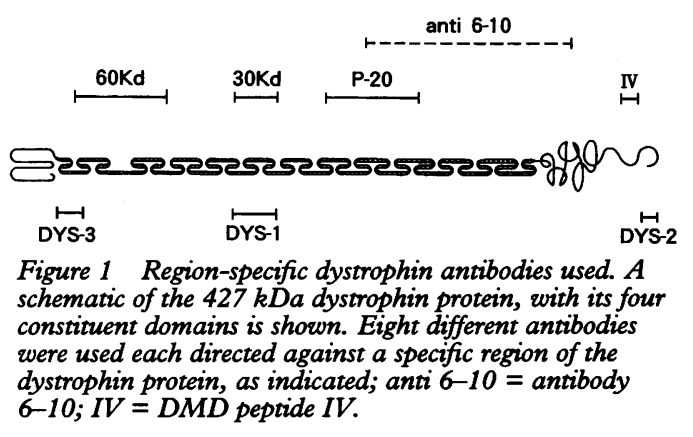

residues 6181-9544. DYS-1, DYS-2, and DYS-3 were monoclonal antibodies raised against the 1181-1388 (mid-rod), 3669-3685 (C-terminal), and 321-494 (N terminal domain) amino acids of dystrophin (fig 1). For immunostaining, tissues were dissected out and frozen in isopentane cooled in liquid nitrogen. Frozen sections $10 \mu \mathrm{m}$ thick were cut and the avidin-DH biotinylated horseradish peroxidase method was performed as described previously. ${ }^{18}$ For the primary incubation, cooled acetone-fixed frozen sections were incubated with dystrophin antibodies at $4^{\circ} \mathrm{C}$ overnight; for secondary incubation, the sections were incubated in affinity-purified secondary antibodies conjugated to avidinDH biotinylated horseradish peroxidase. Sections were examined with an Olympus photomicroscope.

\section{Results}

In tissue from five normal controls, DYS-1, DYS-3, $60 \mathrm{kDa}, 30 \mathrm{kDa}, \mathrm{P}-20$, antibody 6-10, and DMD peptide IV revealed a dystrophin band as pronounced as that of biopsied muscle at $427 \mathrm{kDa}$ in skeletal and cardiac

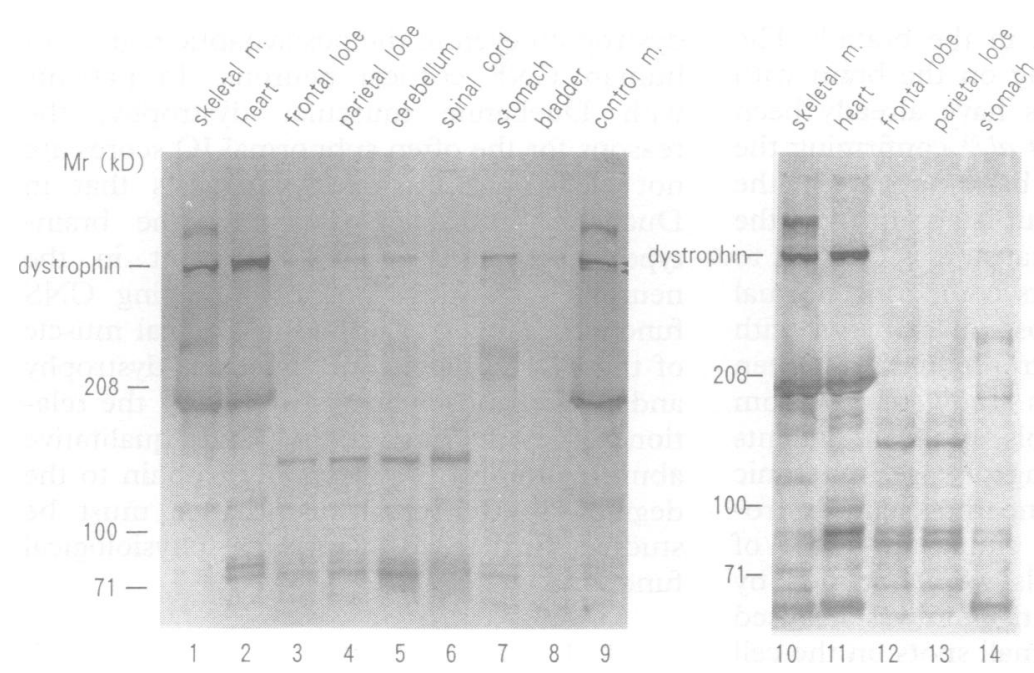

Figure 2 Immunoblot analysis of dystrophin in various tissues of normal controls. Control in (lane 9) = control biopsied skeletal muscle; Lanes 1 to 9 were stained with DYS-1, and lanes 10 to 14 were stained with DYS-2. The location of dystrophin is indicated; the doublet appearance is typical of striated muscle (arrows). The very high molecular weight band (about $500 \mathrm{kDa}$ ) in skeletal muscle is thought to be nebulin as it was present in skeletal muscle but not in heart muscle.

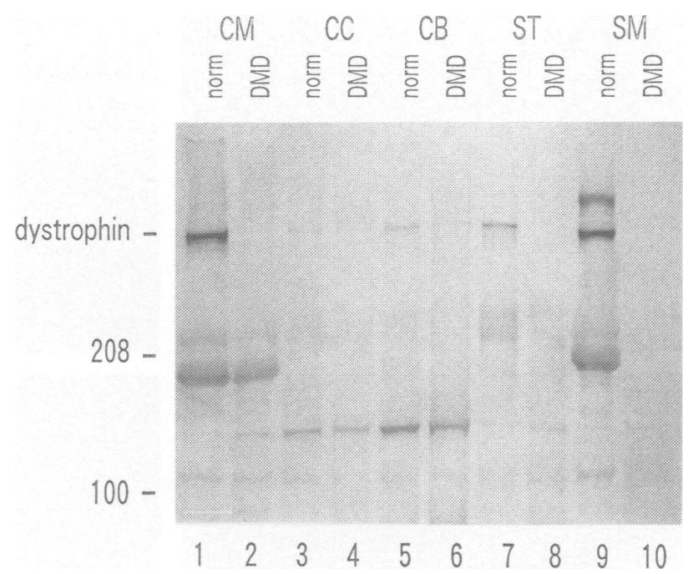

Figure 3 Immunoblot of dystrophin in various tissues from normal controls (norm) and patients with Duchenne muscular dystrophy (DMD). Lanes 1 and 2, cardiac muscle (CM); lanes 3 and 4, cerebral cortex (CC); lanes 5 and 6, cerebellum (CB); lanes 7 and 8, stomach (ST); lanes 9 and 10, skeletal muscle (SM). Blots were stained with dystrophin antibody DYS-1.A dystrophin band was not detected in any tissues of patients with Duchenne muscular dystrophy

muscles, and a less intense dystrophin band in smooth muscle tissues such as the stomach and bladder, and also in the cerebrum (frontal, parietal, and occipital lobes) and cerebellum (fig 2). Only trace amounts were noted in the lung, kidney, liver, and spinal cord. A thin band close to $400 \mathrm{kDa}$ was also found as a doublet with the $427 \mathrm{kDa}$ upper principal band in skeletal and cardiac muscles tested with DYS-1, DYS-3, $60 \mathrm{kDa}, 30 \mathrm{kDa}$, $\mathrm{P}-20$, and antibody $6-10$. On the other hand, only a single band was noted in smooth muscle, cerebrum, and cerebellum, at $427 \mathrm{kDa}$. These results agree fundamentally with those of Byers et $a^{8}$ who used animal models, although they did not study the CNS. With DYS-2, that recognises the C-terminal region, dystrophin was noted as an apparent band in skeletal, cardiac, and smooth muscle, but not in tissues of the brain. On the other hand, because the polyclonal antibody DMD peptide IV cross reacts with a dystrophin-related protein, ${ }^{190}$ a $427 \mathrm{kDa}$ band was noted in the brain as well as in striated and smooth muscles of the controls. In patients with Kennedy-Alter-Sung disease or myotonic dystrophy, dystrophin was also clearly detectable in skeletal, cardiac, and smooth muscles, and in the brain. By contrast, no dystrophin was detected by any antibodies in any tissues, including the cerebrum and cerebellum, of patients with Duchenne muscular dystrophy and with intellectual disturbance (fig 3).

With immunostaining, localisation of the antibody was noted on the surface membrane of skeletal, cardiac, and smooth muscles (fig 4) and punctate along the cell bodies and dendrites of the cerebral cortical neurons and cerebellar Purkinje cells (fig 5). The cerebral cortical neurons and Purkinje cells did not stain positive with DYS-2, but immunoreactivity was noted on the vascular wall. With DMD peptide IV, the neuroglia and vascular 

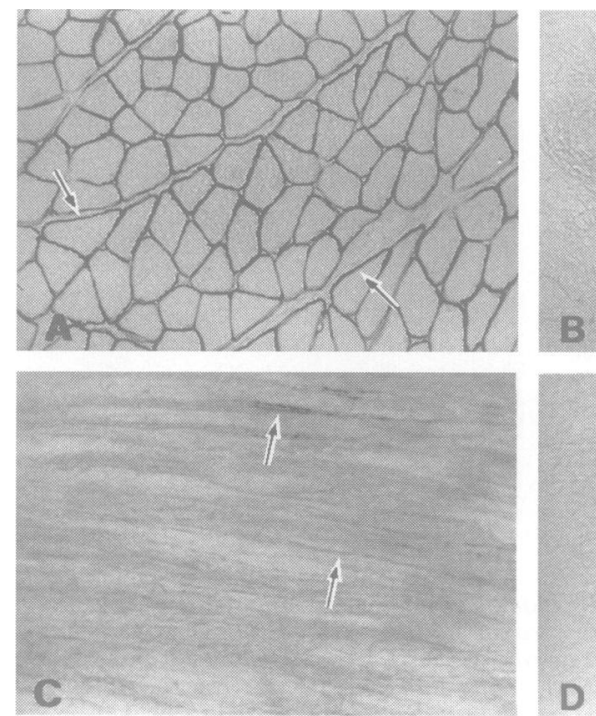

Figure 4 Immunohistochemical localisation of dystrophin. Cryosections $(10 \mu \mathrm{m})$ of skeletal muscle from normal controls $(A)$, skeletal muscle from patients with DMD $(B)$, bladder from normal controls (C), bladder from patients with Duchenne muscular dystrophy (D) labelled with DYS-2. Note the intense dystrophin immunoreactivity of the surface membrane of skeletal and smooth muscle from normal controls (arrows), but no apparent immunoreactivity in tissues from patients with Duchenne muscular dystrophy. Original magnification: $A$ and $B \times 157 ; C$ and $D \times 786$.
It has already been shown that the mRNA of dystrophin is present not only in human skeletal and cardiac muscle but also in small amounts in smooth muscle and brain. ${ }^{22}$ This agrees with the results of our study. By immunoblotting, dystrophin appeared as a doublet in the striated muscle of normal controls, and as a single band in smooth muscle and the brain. As Byers et al reported, the lower band of the doublet in striated muscle seemed to lack a portion of the C-terminal and may represent a dystrophin isoform. ${ }^{8} \mathrm{~A}$ dystrophin band appeared with DYS-1, DYS$3,60 \mathrm{kDa}, 30 \mathrm{kDa}, \mathrm{P}-20$, antibody $6-10$, and DMD peptide IV antibodies in the brain, but not with DYS-2 (recognising the C-terminal region of dystrophin in human skeletal muscle). This is assumed to be due to the fact that the four domains of dystrophin, especially in the C-terminal region, show differences in amino acid composition according to the type of tissue (skeletal muscle or brain). ${ }^{23}$ Thus DYS-2 recognises dystrophin in skeletal, cardiac, and smooth muscle, but not in the brain. Besides the brain-type $(427 \mathrm{kDa})$ dystrophin isoform, several dystrophin isoforms with lower molecular weight ( 70 to $78 \mathrm{kDa}$ ) were recently found. ${ }^{24-26}$ These proteins, so-called apodystrophins, were thought to be a major Duchenne muscular dystrophy gene product in the brain and non-muscle tissues. In our study, however, no clear band was detected at around 70 to $78 \mathrm{kDa}$ in either control or Duchenne muscular dystrophy brains with DYS-2. This may be due to the fact that DYS-2 is a muscle-specific antibody and does not react with brain-type dystrophin or apodystrophins.

By immunoelectron microscopical study, Lidov et $a l^{9}$ reported on the localisation of dystrophin in the postsynaptic membrane of neurons in control mice. As for the human brain, no such findings have been reported, but the similarity between the results of Lidov et al and our immunostaining patterns for humans (as well as those of the rat brain (unpublished data)), indicates the presence of dystrophin even in the postsynaptic regions of human CNS cortical neurons. In patients with Duchenne muscular dystrophy, the reasons for the often subnormal IQ scores are not clear, but this study suggests that in Duchenne muscular dystrophy the braintype dystrophin originally present in the neurons is lacking, possibly affecting CNS function. Thus as clarified in skeletal muscle of those with Duchenne muscular dystrophy and Becker muscular dystrophy, ${ }^{27-29}$ the relation of both quantitative and qualitative abnormalities of brain-type dystrophin to the degree of intellectual disturbance must be studied further to clarify its physiological functions. phy were used. Results similar to those experiments with animals were obtained by immunoblotting, and dystrophin was localised by immunostaining, as small spots on the cell bodies and dendrites of neurons in the brains of normal controls. Dystrophin was absent, however, from patients with Duchenne muscular dystrophy and with intellectual disturbance.

We express cordial thanks to Drs E P Hoffman, L M Kunkel, H G W Lidov, and I Ginjaar for their generous supply of sheep and rabbit dystrophin antibodies. This work was supported by a grant (2-A) from the National Center of Neurology and Psychiatry (NCNP) of the Ministry of Health and Welfare, Japan. 

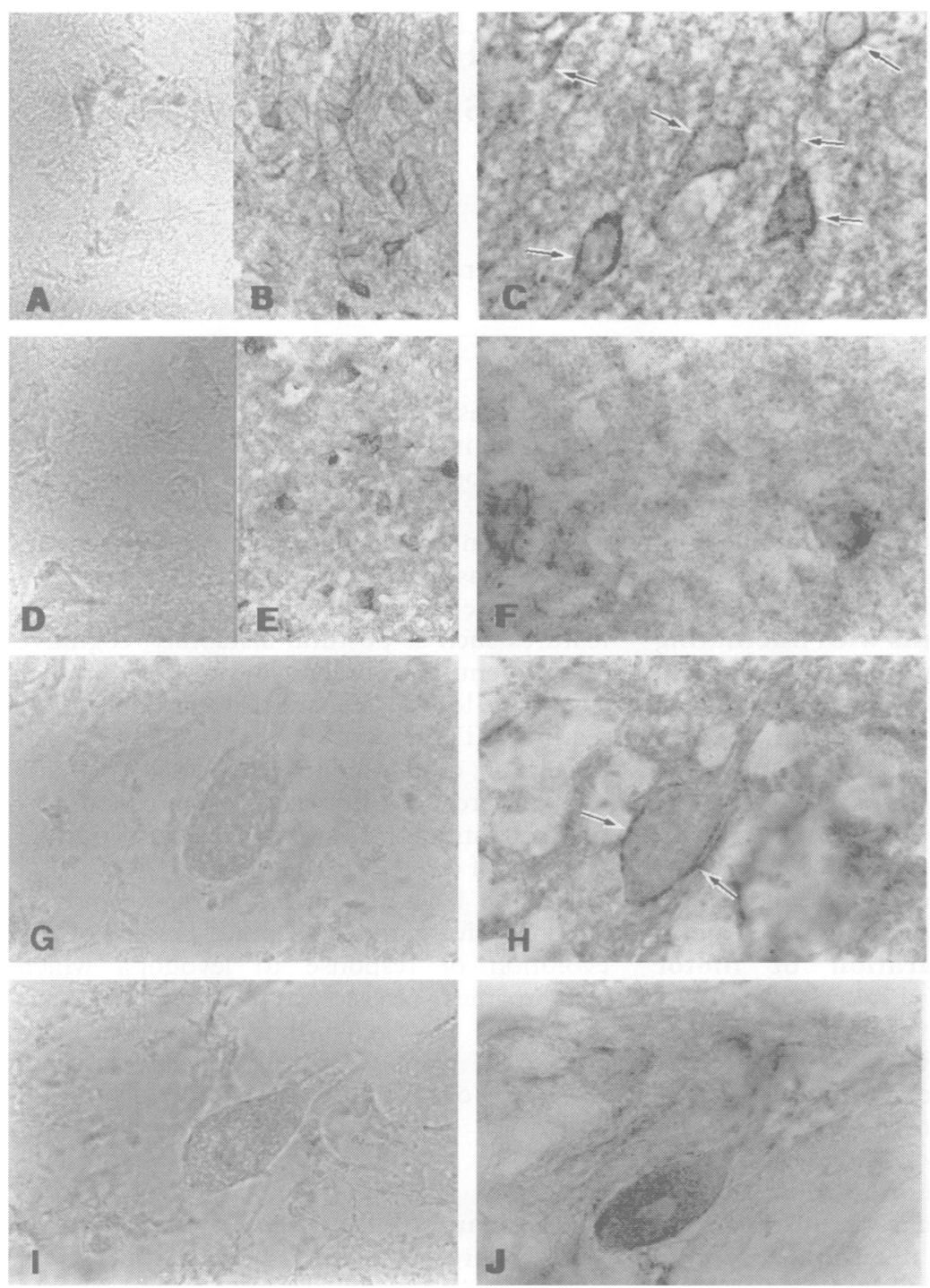

Figure 5 Immunohistochemical localisation of dystrophin in the CNS of tissues from normal controls and from patients with Duchenne muscular dystrophy. Normal control cerebral cortex $(A-C)$, Duchenne muscular dystrophy cerebral cortex $(D-F)$, normal control cerebellum $(G, H)$, and Duchenne muscular dystrophy cerebellum $(I, \mathfrak{F})$, labelled with preimmune serum $(A, D, G$, and I) and antibody 6-10 $(B, C, E, F, H$, and F). Note the punctate immunoreactivity along the cell bodies and dendrites of the cerebral cortical neurons and the cerebellar Purkinje cells in tissue from normal controls (arrows). On the other hand, no immunoreactivity is apparent in tissues from patients with Duchenne muscular dystrophy. Original magnification: $A, C, D, F, G, H, I$, and $\mathcal{F} \times 786 ; B$ and $E \times 238$.

1 Hoffman EP, Knudson CM, Campbell KP, Kunkel LM Subcellular fractionation of dystrophin to the triads of Subcellular fractionation of dystrophin to
skeletal muscle. Nature 1987;330:754-8.

2 Hoffman EP, Brown RH, Kunkel LM. Dystrophin: the protein product of the Duchenne muscular dystrophy locus. Cell 1987;51:919-28.

3 Wessel HB. Dystrophin: a clinical perspective. Pediatr Neurol 1990;6:3-12.

4 Sugita $H$, Arahata $K$, Ishiguro $T$, et al. Negative immunostaining of Duchenne muscular dystrophy (DMD) and mdx muscle surface membrane with antibody against synthetic peptide fragment predicted from DMD cDNA. Proc fpn Acad 1988;64:37-9.
5 Arahata $\mathrm{K}$, Ishiura $\mathrm{S}$, Ishiguro $\mathrm{T}$, et al. Immunostaining of skeletal and cardiac muscle surface membrane with antibody against Duchenne muscular dystrophy peptide. Nature 1988;333:861-3.

6 Zubrzycka-Gaarn EE, Bulman DE, Karpati G, et al. The Duchenne muscular dystrophy gene product is localized in sarcolemma of human skeletal muscle. Nature 1988; in sarcolem

7 Cullen MJ, Walsh J, Nicholson LB, et al. Ultrastructural localization of dystrophin in human muscle by using gold immunolabelling. Proc $R$ Soc Lond 1990;240: 197-210.

8 Byers TJ, Kunkel LM, Watkins SC. The subcellular distribution of dystrophin in mouse skeletal, cardiac, and smooth muscle. F Cell Biol 1991;115:411-21.

9 Lidov HGW, Byers TJ, Watkins SC, Kunkel LM. Localization of dystrophin to postsynaptic regions of central nervous system cortical neurons. Nature 1990; 348:725-8.

10 Allen JE, Rodgin DW. Mental retardation in association with progressive muscular dystrophy. Am $\mathcal{f}$ Dis Child with progressive

11 Worden DK, Vignos PJIr. Intellectual function in childhood progressive muscular dystrophy. Pediatrics 1962 hood progr

12 Dubowitz V. Intellectual impairment in muscular dystrophy. Arch Dis Child 1965;40:296-301.

13 Zellweger H, Niedermeyer E. Central nervous system manifestations in childhood muscular dystrophy. I. Psychometric and electroencephalographic findings. Ann Paediatr (Paris) 1965;205:25-42.

14 Zellweger H, Hanson JW. Psychometric studies in muscular dystrophy type IIIa (Duchenne). Dev Med Child Neurol 1968;9:576-81.

15 Prosser EJ, Murphy EG, Thompson MW. Intelligence and the gene for Duchenne muscular dystrophy. Arch Dis Child 1969;44:221-30.

16 Marsh GG, Munsat TL. Evidence for early impairment of verbal intelligence in Duchenne muscular dystrophy. verbal intelligence in Duchenn

17 Moser H. Duchenne muscular dystrophy: pathogenetic aspects and genetic prevention. Hum Genet 1984;66: $17-40$.

18 Uchino M, Araki S, Miike T, et al. Localization and characterization of dystrophin in muscle biopsy specimens from Duchenne muscular dystrophy and various neuromuscular disorders. Muscle Nerve 1989;12:1009-16.

19 Love DR, Hill DF, Dickson G, et al. An autosomal transcript in skeletal muscle with homology to dystrophin Nature 1989;339:55-8.

20 Khurana TS, Hoffman EP, Kunkel LM. Identification of a chromosome 6-encoded dystrophin-related protein. ¥Biol Chem 1990;265:16717-20.

21 Hoffman EP, Hudecki MS, Rosenberg PA, et al. Cell and fibertype distribution of dystrophin. Neuron 1988;1: $411-20$.

22 Chelly J, Kaplan JC, Maire P, et al. Transcription of the dystrophin gene in human muscle and non-muscle tisdystrophin gene in human m

23 Feener CA, Koenig M, Kunkel LM. Alternative splicing of human dystrophin mRNA generates isoforms at the carboxy terminus. Nature 1989;338:509-11.

24 Blake DJ, Love DR, Tinsley J, et al. Characterization of a $4.8 \mathrm{~kb}$ transcript from the Duchenne muscular dystrophy locus expressed in Schwannoma cells. Hum Mol Genet 1992;1:103-9.

25 Hugnot JP, Gilgenkrantz H, Vincent N, et al. Distal transcript of the dystrophin gene initiated from an alternative first exon and encoding a $75-\mathrm{kDa}$ protein widely distributed in nonmuscle tissues. Proc Natl Acad Sci USA 1992;89:7506-10.

26 Lederfein D, Levy Z, Augier N, et al. A 71-kilodalton protein is a major product of the Duchenne muscular dystein is a major product of the Duchenne muscular dystrophy gene in brain and other nonm

27 Monaco AP, Bertelson CJ, Liechti-Gallati S, et al. An explanation for the phenotypic differences between patients bearing partial deletions of the DMD locus. Genomics 1988;2:90-5.

28 Hoffman EP, Kunkel LM, Angelini C, et al. Improved diagnosis of Becker muscular dystrophy by dystrophin testing. Neurology 1989;39:1011-7.

29 Koenig M, Beggs AH, Moyer M, et al. The molecular basis for Duchenne versus Becker muscular dystrophy: correlation of severity with type of deletion. Am $\mathcal{F}$ Hum Genet 1989;45:498-506. 